\title{
Male Circumcision: A Practice Survey from Saudi Arabia
}

\author{
Osama A. Bawazir ${ }^{1,2}$, FRCSC, FRCSI and Hatem A. Sembawa ${ }^{1}$ \\ 'Department of Surgery, Faculty of Medicine, Umm Al-Qura University \\ Makkah, Saudi Arabia \\ ${ }^{2}$ Department of Surgery, King Faisal Specialist Hospital \& Research Centre \\ Jeddah, Saudi Arabia
}

\section{Correspondence}

Dr. Osama Bawazir

Department of Surgery, Faculty of Medicine

Umm Al-Qura University

P.O. Box 715, Makkah 21955

Saudi Arabia

e-M: obawazir@yahoo.com

Oabawazir@uqu.edu.sa

Submission: 24 Sep. 2019

Accepted: 29 Dec. 2019

\section{Citation}

Bawazir OA, Sembawa HA. Male circumcision: a practice survey from Saudi Arabia. JKAU Med Sci 2019; 26 (2): 45-51. DOI: 10.4197/Med.26-2.5

Copyright: ๑The Author(s), YEAR. Publisher. The Journal of King Abdualziz University - Medical Sciences is an Official Publication of "King Abdulaziz University". It is an open-access article distributed under the terms of the Creative Commons Attribution Non-Commercial License, which permit unrestricted non-commercial use, distribution, and reproduction in any medium, provided the original work is properly cited.

\begin{abstract}
The study aims to evaluate the various techniques used to perform circumcision in Saudi Arabia. In September 2018, this cross sectional survey was performed. A questionnaire were sent to all pediatric surgery units across the Kingdom. The responses to the questionnaire were analyzed and categorized. A total of 176 questionnaires weresend and more than half (56.3\%) of the practitioners filled the questioners, $62(63 \%)$ were consultants, 19 (19\%) were specialists and 19 (19\%) were trainee in pediatric surgery fellowship program. Circumcisions were performed in Maternity and Children hospitals (32.3\%), tertiary hospitals (32.3\%), private hospitals (16\%) and in general or academic hospitals (19\%). The most commonly used method for circumcision was Gomco clamp ( $n=39 ; 39.6 \%)$ followed by plastibell $(n=30 ; 30 \%)$ and bone cutter ( $n=25 ; 25.4 \%)$. The optimal time for circumcision was in neonatal period $.86 \%$ of the surgeons agree that 2.5 to $5 \mathrm{~kg}$ is the optimal weight for the baby to do circumcision.In Saudi Arabia circumcision is a religious practice done for every Muslim male. It should be done by trained medical practitioner and circumcision done by non-medical personal should be avoided. Circumcision should be performed in the neonatal period and attention should be given to analgesia.
\end{abstract}

\section{Keywords}

Circumcision; Survey; Pediatric surgeons

\section{Introduction}

ircumcision is one of the oldest and most common operations performed all over the world with an estimated 25 circumcisions being performed every minute. The prevalence of male circumcision is approximately $37.7 \%$ worldwide ${ }^{[1]}$. The procedure, which involves the surgical removal of the prepuce (foreskin) either in whole or in part, has evolved from being a rite of passage into manhood to being a symbol of faith, mainly among Muslims and Jews ${ }^{[2]}$. However, from the late 19th century onwards, it gained global popularity in the field of public health as having protective effects against penile infection, carcinoma and venereal diseases ${ }^{[3]}$. The adoption of circumcision to clinical settings has also reduced the risk of complications from traditional ceremonial practices. Though the procedure is prevalent among adolescents and adults, infancy presents a "window of opportunity" for circumcision with lower costs, lesser pre- and 
post-operative complications, quicker healing, and superior cosmetic and health benefits ${ }^{[4]}$. A standard surgical protocol involves asepsis, excision of outer and inner preputial skin layers, hemostasis, protection of the glans and urethra, and cosmesis. The methods employed for circumcision are classified into three main types, such as dorsal slit, shield and clamp, and excision or their combinations. The shield and clamp adopt the use of devices to effect circumcision with minimal usage of knife and is a method of choice for infants ${ }^{[5]}$. In situ devices (clamps and collar compressor for adults) compress the foreskin between two surfaces, thereby stopping bleeding and allowing the foreskin to be removed at the time of device placement or after necrosis of the foreskin has occurred (Plastibell device $[P D]$ for infants), mostly after a week.

Male circumcision (MC) being a complementary method in HIV prevention also indirectly reduces the risk of exposure in women. The World Health Organization (WHO) and the Joint United Nations Programme on HIV and AIDS (UNAIDS) advocated for adolescent and adult voluntary medical male circumcision (VMMC) as part of comprehensive HIV prevention programs. With the present focus on early infant male circumcision (EIMC) as a means to achieve sustainability of VMMC, WHO published the Manual for Early Infant Male Circumcision under Local Anesthesia in $2010^{[6]}$. However, in regions with less HIV and sexually transmitted infection (STI) endemicity, awareness on different circumcision methods with its associated benefits and risks is critical to making informed choices. No devices or specific techniques are reported to be superior to the other, and each has its own advantages and disadvantages. Circumcision can result in early (intraoperative) or late (postoperative) complications, but serious complications are extremely rare. Complication rates ranging from $1.4 \%$ to $1.6 \%$ have been reported in Muslim-majority countries. However, the rates of reported complications vary greatly between studies, depending on the training and experience of providers, age of the subject, surgical procedure, sterility of the setting, and data collection methods ${ }^{[7,8]}$.

In Saudi Arabia, $97.1 \%$ of males undergo circumcision in the neonatal period mainly for religious reasons; cultural and educational influences also play an important role ${ }^{[9]}$. Despite this high prevalence, there is a lack of systematic surveys on the clinical practices associated with the procedure that could facilitate consensus models for safe and effective circumcision. Such reviews are of paramount significance when several global health care policies assess the feasibility and safety of introducing EIMC services into health facilities as part of Maternal, Newborn and Child Health programs $s^{[4]}$. The present study has therefore gathered information and opinions from experienced clinicians to evaluate the various principles and practice methods employed in circumcision across different hospitals in the country.

\section{Materials and Methods}

In January 2018, questionnaires containing 24 multiplechoice questions were sent to all pediatric surgery units across the Kingdom of Saudi Arabia. The questionnaire, approved by the institutional review board, requested information from health-care providers about several aspects of neonatal circumcision. Further, the responses were analyzed and categorized as shown in the results section.

\section{Results}

A total of 176 questionnaires were distributed, and of them, 99 (56.3\%) questionnaires were addressed by practitioners. The respondents included 62 (63\%) consultants, 19 (19\%) specialists, and 19 (19\%) trainees in the pediatric surgery fellowship program. All of them performed 25 to 100 circumcisions per year at maternity and children's hospitals ( $n=32 ; 32.3 \%$ ), tertiary hospitals $(n=32 ; 32.3 \%)$, private hospitals ( $n$ $=16 ; 16 \%)$, and general or academic hospitals $(n=19$; 19\%) (Table 1).

\section{Techniques of Circumcision}

The most commonly used method for circumcision was Gomco clamp ( $n=39 ; 39.6 \%)$, followed by PD $(n=30$; $30 \%)$ and bone cutter ( $n=25 ; 25.4 \%)$ (Fig. 1).

\section{Age and Weight of the Baby at the Time of Circumcision}

The optimal time for circumcision is in the neonatal period (before discharge $[n=26 ; 26 \%]$, first week $[n=$ $32 ; 32 \%]$ and within the 1 st month of life $[n=33 ; 33 \%])$ (Table 2). Eighty-six (86\%) out of 99 surgeons agreed 
that 2.5 to $5 \mathrm{~kg}$ is the optimal weight for the baby to undergo circumcision (Fig. 2). Most of the practitioners do not perform the surgery if the baby's age is $>2$ months ( $n=32 ; 32.6 \%)$ and $\geq 4$ months $(n=67 ; 67.8 \%)$ or if the weight is $>5 \mathrm{~kg}(\mathrm{n}=81 ; 81.4 \%)$.

Table 1. Types of the hospitals where the circumcisions were done

\begin{tabular}{|l|c|c|}
\hline \multicolumn{1}{|c|}{ Hospitals } & Frequency & Percentage (\%) \\
\hline Pediatric hospitals & 32 & 32.3 \\
\hline Tertiary hospitals & 32 & 32.3 \\
\hline Private hospitals & 16 & 16.2 \\
\hline General hospitals & 14 & 14.1 \\
\hline Academic hospitals & 5 & 5.1 \\
\hline Total & 99 & 100 \\
\hline
\end{tabular}

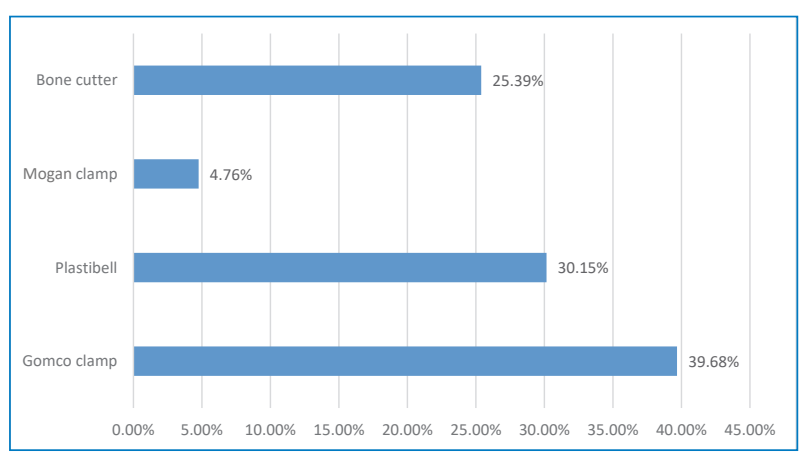

Figure 1. Types of techniques used in circumcisions.

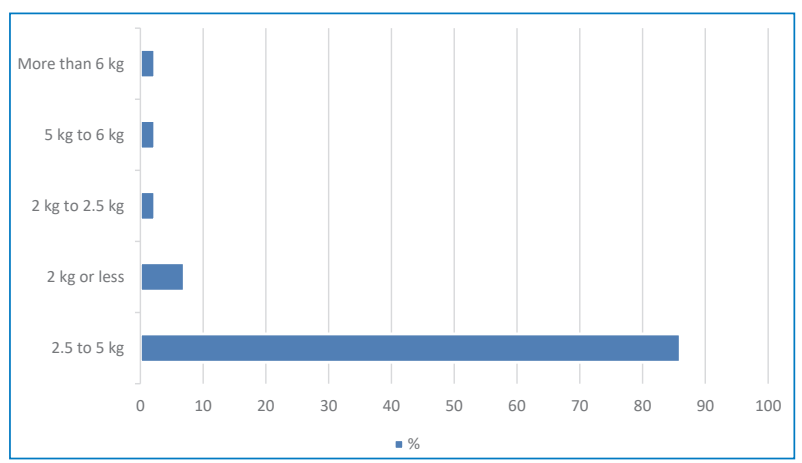

Figure 2. Optimal baby weight from the surgeon's perspective.

\section{Surgical settings}

In $80 \%(n=80)$ of the patients of different ages, circumcision was done in a clinic or a day surgery suite ( $1^{\text {st }}$ week $[\mathrm{n}=12 ; 12 \%], 8-30$ days $[\mathrm{n}=52 ; 52 \%]$ and 2 to 4 months $[n=16 ; 16 \%])$. Only in $19 \%(n=19)$ of the cases, circumcision was done in the nursery before discharge from the hospital (Table 3). Circumcisions were done by a registrar or assistant consultant $(n=72$; $72 \%)$ and by consultant $(\mathrm{n}=28 ; 28 \%)$ mainly in private hospitals (Table 4).

\section{Anesthesia and Analgesics}

For local anesthesia, practitioners use dorsal penial block ( $\mathrm{n}=49 ; 49 \%)$ using Xylocaine injection $1 \mathrm{mg} / \mathrm{Kg}$, EMLA cream application $(n=37 ; 37 \%)$, and Xylocaine spray $(n=4 ; 4 \%)$, while $9 \%(n=9)$ were noncompliant (Table 5). Adol drops or suppositories were commonly used for analgesia ( $n=62 ; 62.6 \%)$, followed by dextrose oral solution $(n=21 ; 21.2 \%)$ (Table 6).

\section{DISCUSSION}

Circumcision is a widespread practice greatly influenced by cultural and religious traditions. Muslims are currently the largest single religious group in which the practice of circumcision is widespread, especially in Arabic-speaking countries ${ }^{[10]}$. The main reason given for the ritual is cleanliness and hygiene. It is essential that every Muslim cleans himself before praying and that no urine should be left on the body. Removal of the foreskin makes it easier to keep the penis clean, avoiding urine or any secretions to be trapped there. According to the World Health Organization (WHO), global estimates suggest that $30 \%$ of males are circumcised, of whom $68 \%$ are Muslims. In Saudi Arabia, 97.1\% of newborns are circumcised ${ }^{[11]}$. There are other reasons for circumcision, including decreasing the incidence of urinary tract infection and balanitis. Reduction in ulcerative sexually transmitted diseases ${ }^{[12,13]}, \mathrm{HIV}^{[14]}$, and HPV ${ }^{[15]}$ has also been reported. The use of circumcision for medical or health reasons

Table 2. Optimal time of circumcision from the surgeon's prospective

\begin{tabular}{|c|c|c|c|c|}
\hline Optimal Time & Frequency & Percent & Valid Percent & Cumulative Percent \\
\hline (8-30) days (within the 1st month) & 32 & 32.3 & 32.3 & 32.3 \\
\hline Before discharge home (1 to 2 day) in nursery & 26 & 26.3 & 26.3 & 58.6 \\
\hline 1st week & 23 & 23.3 & 23.3 & 81.9 \\
\hline At 7 days & 9 & 9 & 9 & 90.9 \\
\hline From 2 to 4 month & 9 & 9 & 9 & 100.0 \\
\hline Total & 99 & 100.0 & 100.0 & \\
\hline
\end{tabular}


Table 3. Areas where circumcision done

\begin{tabular}{|c|c|c|c|c|}
\hline Areas Where Circumcision & Frequency & Percent & Valid Percent & Cumulative Percent \\
\hline Nursery (in-patient) & 19 & 19.2 & 19.2 & 19.2 \\
\hline Clinic (out-patient) & 31 & 31.3 & 31.3 & 50.5 \\
\hline Procedural clinic & 15 & 15.1 & 15.1 & 65.6 \\
\hline Day surgery & 35 & 35.4 & 35.4 & 100.0 \\
\hline Total & 99 & 100.0 & 100.0 & \\
\hline
\end{tabular}

Table 4. Experience of the practitioner

\begin{tabular}{|l|c|c|c|c|}
\hline \multicolumn{1}{|c|}{ Experience of the Practitioner } & Frequency & Percent & Valid Percent & Cumulative Percent \\
\hline Your assailant registrar or senior registrar & 63 & 63.6 & 63.6 & 63.6 \\
\hline You & 27 & 27.3 & 27.3 & 90.9 \\
\hline Your trainee resident & 9 & 9.1 & 9.1 & 100.0 \\
\hline \multicolumn{1}{|c|}{ Total } & 99 & 100.0 & 100.0 & \\
\hline
\end{tabular}

Table 5. Types of anesthesia used

\begin{tabular}{|l|c|c|c|c|}
\hline \multicolumn{1}{|c|}{ Types of Anesthesia } & Frequency & Percent & Valid Percent & Cumulative Percent \\
\hline Local injection e.g., Xylocaine & 48 & 48.5 & 48.5 & 48.5 \\
\hline Emla cream & 38 & 38.4 & 38.4 & 86.9 \\
\hline None & 9 & 9.1 & 9.1 & 96 \\
\hline Xylocaine spray & 4 & 4 & 4 & 100.0 \\
\hline \multicolumn{1}{r|}{ Total } & 99 & 100.0 & 100.0 & \\
\hline
\end{tabular}

Table 6. Types of analgesics used

\begin{tabular}{|c|c|c|c|c|}
\hline Type of Analgesia Used & Frequency & Percent & Valid Percent & Cumulative Percent \\
\hline Adol drop & 62 & 62.6 & 62.6 & 62.6 \\
\hline Dextrose & 21 & 21.2 & 21.2 & 83.8 \\
\hline None & 16 & 16.2 & 16.2 & 100.0 \\
\hline Total & 99 & 100.0 & 100.0 & \\
\hline
\end{tabular}

is an issue that continues to be debated. The American Academy of Pediatrics found that the health benefits of newborn male circumcision outweigh the risks, but the procedure was not found to be essential to a child's well-being, justifying its access only upon personal choice. Researchers have shown that the foreskin is enriched with HIV-1 target cells, providing biological evidence for the decrease in the risk of HIV infection by male circumcision, which was first proposed in 1986. These beneficial effects are more relevant for high HIVand STI-endemicity settings. Therefore, adolescent and adult VMMC and, more recently, EIMC are advocated by public health agencies such as WHO and UNAIDS. Routine circumcision in the neonates are performed safely, but higher complication rates are reported with increasing age. The main complications due to the procedure of operation are wound dehiscence, postoperative bleeding, urinary retention and infection, which in most cases are avoidable. Awareness about the various procedures is critical to making informed choices for safe and effective circumcision. Though comparison of different devices used for circumcision in Saudi Arabia has been reported before, the present work is unique in that we have gathered information from experienced practitioners and evaluated the various aspects of the procedure, such as the experience of the provider, vital status of the client, surgical methods, analgesics, etc. as performed across different hospitals across the country.

According to this survey, most pediatric surgeons believe that the best time of circumcision is in the neonatal period (90\%). Circumcision in the neonatal period is associated with substantially lower costs and lower risk of complications, and an assurance of greatly reduced risk of penile cancer and various STIs later in life, no smegma, and improved hygiene ${ }^{[3]}$. The present study reports corroborate with earlier studies that 
indicate higher prevalence of neonatal circumcision in Saudi Arabia, thus validating the efficacy of the study procedure. In Saudi Arabia, circumcision is done in the neonatal period, unless there is a medical reason to delay circumcision such as congenital anomaly or prolonged jaundice. In the past, circumcision was usually performed in a non-clinical setting by a traditional provider with no formal medical training. Currently, circumcision is mostly done by pediatric surgeons, general surgeons and/or urologists. The timing of elective newborn circumcision is still controversial but, when done before hospital discharge, it was not associated with a decrease in exclusive breastfeeding among military mothers and babies in the first 2 weeks of life ${ }^{[16]}$. In this survey, circumcision was done in the neonatal period, and $19 \%$ of circumcisions were done in the nursery before discharge from the hospital. This is to avoid any delay mainly because of the difficulties to arrange for the procedure subsequently. Following discharge from the hospital, most circumcisions were done in clinics or as booked procedures in a day surgery.

Gomco clamp is the most commonly used method to do circumcision, followed by PD. As reported earlier by some authors, though PD is widely used in neonates across the world, both physicians and parents in Saudi Arabia opt for conventional techniques, such as the Gomco or bone cutter ${ }^{[17]}$. However, the present survey indicates a preference for PD over the bone cutter. Unlike the shield and clamp procedure of the Gomco clamp or PD, the bone cutter method is blind and known to be associated with frequent tragic complications like amputation of glans, bleeding, and urethra-cutaneous fistula. However, it is still being used by $25 \%$ of medical practitioners. This survey did not include circumcision performed outside hospitals by non-medical practitioners; this practice still persists and is known to be associated with morbidity and should thus be avoided.

The impact of pain and the psychological implications for infants undergoing circumcision are unknown ${ }^{[18,19]}$. It is well known that newborns demonstrate a strong endogenous reaction to pain during circumcision, and therefore, different modalities were used for pain relief during circumcision ${ }^{[2]}$. In this survey, it was standard to use some form of anesthesia, mainly dorsal penial block $(n=49 ; 49 \%)$ and EMLA cream application $(n=37 ; 37 \%)$. The dorsal penile nerve block (Xylocaine injection $1 \mathrm{mg} / \mathrm{kg}$ ) is the best described and studied technique and has a low rate of minor complications, while EMLA application is mostly preferred with PD-assisted circumcision. Adol drops (15 mg $/ \mathrm{Kg}$ ) or suppositories were commonly used for analgesia ( $n=62 ; 62.6 \%)$. As per the WHO guidelines, local anesthesia alone should be used for most infants ( $<1$ year of age). Due to serious risks associated with sedation, it is not recommended for clinic-based circumcision and should be provided under specifically equipped clinical settings.

\section{Conclusion}

In conclusion, circumcision is a religious practice done for every Muslim male in Saudi Arabia. It should be done by trained medical practitioners, and traditional circumcision done by non-medical personal should be avoided. Gomco and PD are the most commonly used techniques. Circumcision should be performed in the neonatal period, and attention should be given to decrease the pain, discomfort and possible psychological trauma associated with circumcision. A large prospective, randomized, controlled trial is important to help standardize the practice of circumcision in Saudi Arabia by the Ministry of Health.

\section{Conflict of Interest}

The authors have no conflict of interest.

\section{Disclosure}

The authors did not receive any type of commercial support either in forms of compensation or financial for this study. The authors have no financial interest in any of the products or devices, or drugs mentioned in this article.

\section{Ethical Approval}

The study design was reviewed and approved by the Unit of Biomedical Ethics Research Committee at King Abdulaziz University.

\section{References}

[1] Hammond T. A preliminary poll of men circumcised in infancy or childhood. BJU Int 1999; 83 Suppl 1: 85-92.

[2] Doyle D. Ritual male circumcision: a brief history. J R Coll Physicians Edinb 2005; 35(3): 279-285.

[3] Morris BJ, Waskett JH, Banerjee J, Wamai RG, Tobian AA, Gray $\mathrm{RH}$, Bailis SA, Bailey RC, Klausner JD, Willcourt RJ, Halperin DT, Wiswell TE, Mindel A. A 'snip' in time: what is the best age to circumcise? BMC Pediatrics 2012; 12: 20. 
[4] Al Qahtani R, Abu-Salem LY, Pal K. Effect of lidocaineprilocaine eutectic mixture of local anesthetic cream compared with oral sucrose or both in alleviating pain in neonatal circumcision procedure. Afr J Paediatr Surg. 2014; 11(1): 56-61.

[5] Abdulwahab-Ahmed A, Mungadi IA. Techniques of male circumcision. J Surg Tech Case Rep 2013; 5(1): 1-7.

[6] Bailey RC, Nyaboke I, Otieno FO. What device would be best for early infant male circumcision in east and southern Africa? Provider experiences and opinions with three different devices in Kenya. PLoS One 12(2): e0171445

[7] Anwer AW, Samad L, Iftikhar S, Baig-Ansari N. Reported male circumcision practices in a Muslim-majority setting . Biomed Res Int 2017; 2017: 1-8.

[8] Friedman B, Khoury J, Petersiel N, Yahalomi T, Paul M, Neuberger A. Pros and cons of circumcision: an evidence-based overview. Clin Microbiol Infect 2016; 22(9): 768-774.

[9] Morris BJ, Wamai RG, Henebeng EB, Tobian AA, Klausner JD, Banerjee J, Hankins CA. Estimation of country-specific and global prevalence of male circumcision. Popul Health Metr 2016; 14: 4.

[10] Weiss HA, Quigley MA, Hayes RJ. Male circumcision and risk of HIV infection in sub-Saharan Africa: a systematic review and meta-analysis. AIDS 2000; 14(15): 2361-2370.

[11] "Circumcision", the Columbia Encyclopedia. 2001; Sixth Edition.

[12] Abu Daia JM, De Castro R. Plastibell: A quick technique to decrease the distress of neonatal circumcision. Saudi Med J 1999; 20(11): 848-851.

[13] Moses S, Bailey RC, Allan RR. Male circumcision: assessment of health benefits and risks. Sex Transm Infect 1998; 74(5): 368-373.

[14] Van Howe RS. Genital ulcerative disease and sexually transmitted urethritis and circumcision: a meta-analysis. Int J STD AIDS 2007; 18(12): 799-809.

[15] Nielson CM, Schiaffino MK, Dunne EF, Salemi JL, Giuliano AR. Associations between male anogenital human papillomavirus infection and circumcision by anatomic site sampled and lifetime number of female sex partners. J Infect Dis. 2009; 199(1): 7-13.

[16] Mondzelewski L, Gahagan S, Johnson C, Madanat H, Rhee K. Timing of circumcision and breastfeeding initiation among newborn boys. Hosp Pediatr 2016; 6(11): 653-658.

[17] Bawazir OA. A controlled trial of Gomco versus Plastibell for neonatal circumcisions in Saudi Arabia. Int J Pediatr Adolesc Med 2019 (in press).

[18] Grimes DA. Routine circumcision of the newborn infant: a reappraisal. Am J Obstet Gynecol 1978; 130(2): 125-129.

[19] Kirya C, Werthmann MW Jr. Neonatal circumcision and penile dorsal nerve block-a painless procedure. J Pediatr 1978: 92(6): 998-1000. 


\section{ختان الأكور: دراسة استقصائية ممارسة من المملكة العربية السعودية}

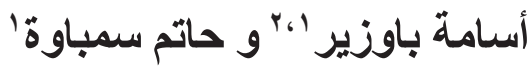

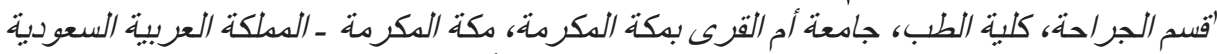

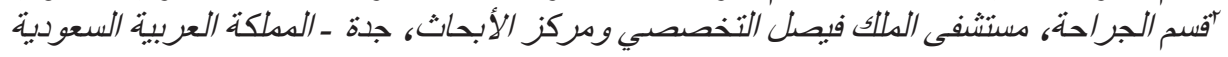

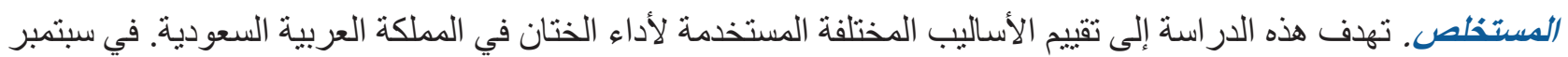

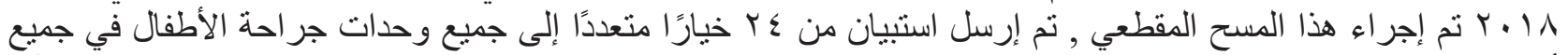

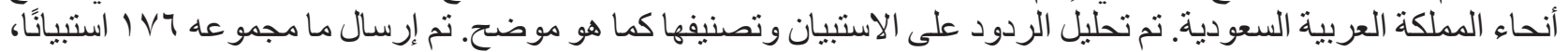

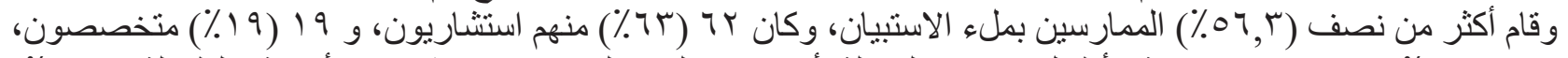

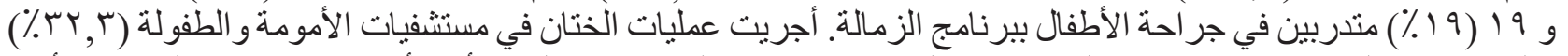

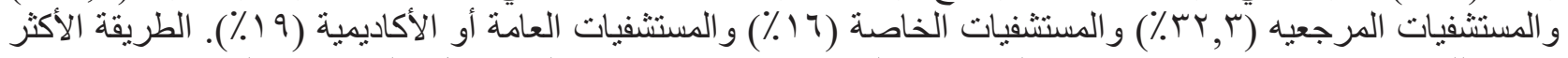

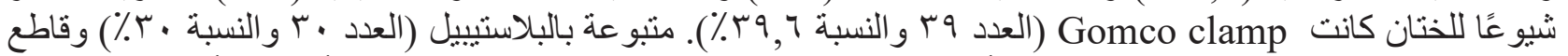

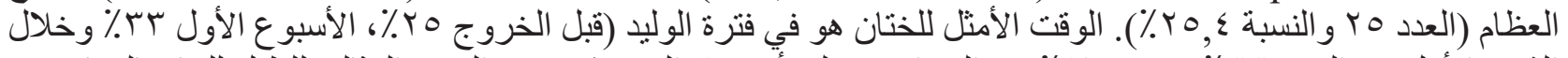

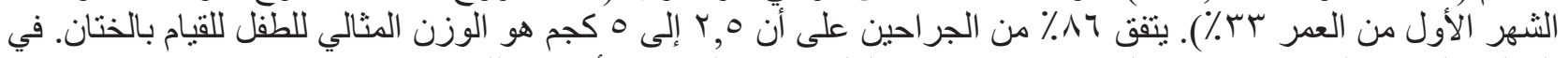

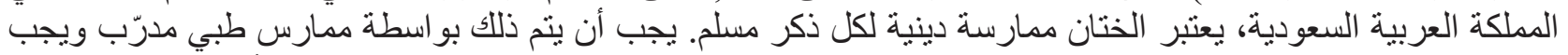

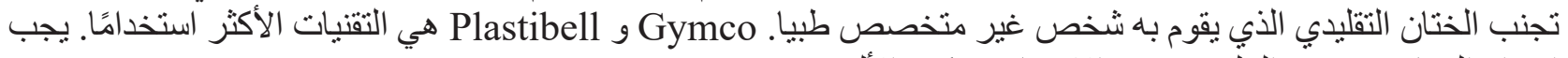
إجراء الختان في فترة الولُيد وينبغي الاهتمام بتسكين الألم. 